Aim of the study: To evaluate the effect of combined use of rapamycin and cisplatin against Hela cells in vitro.

Material and methods: The inhibitory effects of rapamycin and cisplatin, used alone or combination, on the proliferation of Hela cell were measured with MTT assay and median-effect plot analysis. Results: Combined use of rapamycin and cisplatin significantly improved the chemotherapeutic effect against Hela cells. The inhibitory rates were dose-dependent. Rapamycin and cisplatin showed synergistic effects in the chemotherapy of Hela cells ( $q>1.15$, King's formula).

Conclusions: Combined use of rapamycin and cisplatin significantly improves the chemotherapeutic effect against Hela cells.

Key words: rapamycin, cisplatin, cervical carcinoma, Hela cells.

\section{Effect of combination of rapamycin and cisplatin on human cervical carcinoma Hela cells}

\author{
Lu Han', Jie-Ling Wu², Li-Xiao Yang ${ }^{3}$
}

1Dalian Obstetrics and Gynecology Hospital, Dalian, Liaoning, China 2Dalian Blood Center, Dalian, China

3Maternal and Child Health Hospital, Fangshan District, Beijing, China

\section{Introduction}

As the traditional treatment means of cervical carcinoma, operative treatment is limited to early patients. Although radiotherapy can be used for most medium and advanced patients, it is always ineffective for recurrent advanced patients after radiotherapy. The role of chemotherapy in the treatment of cervical carcinoma is increasing, and it is mainly used for patients receiving new adjuvant chemotherapy and advanced or recurrent patients. However, its apparent side effects and drug resistance [1] are also the main reasons why advanced patients cannot adhere to treatment. With increasing understanding of tumor at the cell and molecule level, molecular targeted therapy is of increasing importance. mTOR is the most popular therapeutic target of malignant tumor in current studies. It has been proved that mTOR inhibitor rapamycin (Rapa) and its derivatives have an inhibitory effect on a variety of tumors such as endometrial carcinoma, metastatic renal cell carcinoma, lymphoma, etc. [2-4]. However, the curative effect is poor for gastroenteric tumor [5]. Domestic and foreign researchers have begun to combine the mTOR inhibitor rapamycin with hormones, chemotherapy drugs or other methods to treat tumors and investigate whether combination application of it and chemotherapy drugs has a synergistic effect and whether the reduced side effects of chemotherapy drugs caused by decrease of their dose can reduce or reverse the resistance to chemotherapy drugs $[6,7]$.

In this study, the combination of the mTOR inhibitor rapamycin with cisplatin was used to affect cervical carcinoma Hela cells cultured in vitro to investigate its inhibitory effect on the growth situation of cervical carcinoma Hela cells and analyze the effectiveness of drug combination. In the investigation the combination of the lowest concentration of rapamycin and cisplatin was used to achieve the most apparent inhibitory effect on cervical carcinoma Hela cells cultured in vitro in order to provide a new idea and method for the further clinical application of rapamycin and provide a theoretical basis for developing the new combination chemotherapy regimen of cervical carcinoma in clinical practice.

\section{Material and methods}

\section{Cell culture}

Hela cells were cultured in PRMI 1640 (Gibco) culture medium containing $10 \%$ fetal bovine serum, $100 \mathrm{U} / \mathrm{ml}$ penicillin and $100 \mathrm{mg} / \mathrm{l}$ streptomycin in an incubator containing $5 \% \mathrm{CO}_{2}(\mathrm{~V} / \mathrm{V})$ at $37^{\circ} \mathrm{C}$, and cell growth situations were observed. When the cells grew and covered $70 \%$ 80\% of the culture bottle wall, $0.25 \%$ trypsase was used for digestion, and timely passage was conducted. Subsequently, the cells were continuously cultured. Finally, the cells in logarithmic growth phase were selected for trials. 


\section{Drug intervention}

On the day before administration, the cells were digested with trypsase and counted. The cells $\left(2 \times 10^{6}\right.$ cells $\left./ \mathrm{ml}\right)$ were spread onto a 96-well plate to make the cell density on administration day be $70 \% \sim 80 \%$. After the cells adhered onto the wall, different concentrations of complete media of $200 \mu$ l were added into each well. Next, the cells were incubated in the incubator containing $5 \% \mathrm{CO}_{2}$ at $37^{\circ} \mathrm{C}$ for $48 \mathrm{~h}$.

Different concentrations of drugs were added into the cells. In the simple drug administration experiment, the whole group was divided into the cell control group, rapamycin group and cisplatin group. For the cell control group, the cells were cultured in the equivalent medium without a drug. For the rapamycin group, 4 concentration gradients were applied: $10 \mathrm{nmol} / \mathrm{ml}, 20 \mathrm{nmol} / \mathrm{ml}, 40 \mathrm{nmol} / \mathrm{ml}$ and $80 \mathrm{nmol} / \mathrm{ml}$. For the cisplatin group, 4 concentration gradients were applied: $0.125 \mathrm{mg} / \mathrm{ml}, 0.25 \mathrm{mg} / \mathrm{ml}, 0.50 \mathrm{mg} / \mathrm{ml}$ and $1.00 \mathrm{mg} / \mathrm{ml}$. In addition, in 3 wells only culture liquid was added.

For the drug combination experiment, inhibitory effects of the combinations of $10 \mathrm{nmol} / \mathrm{ml}$ and $20 \mathrm{nmol} / \mathrm{ml}$ rapamycin with $0.25 \mathrm{mg} / \mathrm{ml}$ and $0.50 \mathrm{mg} / \mathrm{ml}$ cisplatin on the cells were respectively detected.

\section{MTT}

After the drugs affected the cells for $48 \mathrm{~h}, 15 \mu$ l of MTT $(5 \mathrm{mg} / \mathrm{ml})$ was added into each well. After incubation for $4 \mathrm{~h}$ at room temperature, $100 \mu \mathrm{l}$ of DMSO was added into each well. After gently shaking for $10 \mathrm{~min}$, the absorbance value of each well was immediately detected with the microplate reader at $589 \mathrm{~nm}$. Trials were repeated three times, and absorbance values of various repeated wells were averaged. Finally, the inhibition ratio of each group of cells (\%) was calculated: inhibition ratio of tumor cell proliferation $=(1-$ absorbance value of drug administration group $/$ absorbance value of the treatment group) $\times 100 \%$.

Jin's formula $q=E a+b /(E a+E b-E a \times E b)$ was used to evaluate whether two drugs had a synergistic effect. Ea $+b$ represented the inhibition ratio of the combination group shozhe, and Ea and Eb represented respectively the inhibition ratios of simple drug a and simple group $b$. If the calculated q value was between 0.85 and 1.15 , the effect of combination of two drugs was the simple summation of respective effects; if $q>1.15$, the two drugs had a synergistic effect; if $q<0.85$, the two drugs had an antagonistic effect.

\section{Results}

Inhibitory effects of simple rapamycin and cisplatin and their combination on growth of cervical carcinoma Hela cells

After rapamycin affected cervical carcinoma Hela cells for $48 \mathrm{~h}$, it had an apparent inhibitory effect on their growth. This inhibitory effect was dose-dependent, and it was more apparent with increase of drug concentration. Between various drug groups and the control group, there were significant differences $(p<0.05)$. Comparison of the result between two adjacent concentration groups showed that there was a significant difference between the $10 \mathrm{nmol} / \mathrm{ml}$ group and the $20 \mathrm{nmol} / \mathrm{ml}$ group $(p<0.05)$, and there was no significant difference between two other adjacent concentration groups.
After cisplatin affected the cells for $48 \mathrm{~h}$, compared with the control group, the inhibition ratio increased. It was suggested that cisplatin had an apparent inhibitory effect on growth of cervical carcinoma Hela cells. This inhibitory effect was dose-dependent, and between various drug groups and the control group, there were significant differences $(p<0.05)$. Comparison of the result between two adjacent concentration groups showed that there were significant differences between two groups among the $0.25 \mathrm{mg} / \mathrm{ml}$ group, $0.50 \mathrm{mg} / \mathrm{ml}$ group and $1.00 \mathrm{mg} / \mathrm{ml}$ group ( $p<0.05$ ), and there was no significant difference between two other adjacent concentration groups.

According to the ratios of inhibition of two simple drugs on Hela cells, drug concentrations in the case of drug combination were selected. As drug combinations, $10 \mathrm{nmol} / \mathrm{ml}$ and $20 \mathrm{nmol} / \mathrm{ml}$ rapamycin were respectively combined with $0.25 \mathrm{mg} / \mathrm{ml}$ and $0.50 \mathrm{mg} / \mathrm{ml}$ cisplatin to affect cervical carcinoma Hela cells. Comparisons of various drug groups with the control group and comparisons between two adjacent concentration groups showed that there were significant differences $(p<0.05)$ (Table 1).

\section{Calculation of the synergistic effect of the two drugs according to Jin's formula}

In terms of the ratios of inhibition of two simple drugs and their combination on Hela cells, it was calculated according to Jin's formula $q=\mathrm{Ea}+\mathrm{b} /(\mathrm{Ea}+\mathrm{Eb}-\mathrm{Ea} \times \mathrm{Eb})$ whether the two drugs had a synergistic or antagonistic effect. Ea $+b$ represented the inhibitory ratio of the combination group, and Ea and Eb respectively the inhibition ratios of simple drug $a$ and simple group $b$. If the calculated $q$ value was between 0.85 and 1.15 , the effect of combination of two drugs was the simple summation of respective effects; if $q>1.15$, the two drugs had a synergistic effect; if $q<0.85$, the two drugs had an antagonistic effect. As a result, in the case of the combination of rapamycin and cisplatin, $q$ values all were more

Table 1. The influence of rapamycin and cisplatin individually or combined on the growth of Hela cells in vitro

\begin{tabular}{|c|c|c|}
\hline Group & Absorbance $A(X \pm S)$ & Inhibition rate (\%) \\
\hline control & $0.7012 \pm 0.0201$ & 0 \\
\hline \multicolumn{3}{|c|}{ rapamycin (nmol/ml) } \\
\hline 10 & $0.6160 \pm 0.0325$ & $12.15^{\star \Delta}$ \\
\hline 20 & $0.5459 \pm 0.0318$ & $22.14^{\star \Delta}$ \\
\hline 40 & $0.5173 \pm 0.0126$ & $26.23^{*}$ \\
\hline 80 & $0.4759 \pm 0.0218$ & $32.23^{*}$ \\
\hline \multicolumn{3}{|c|}{ cisplatin (mg/ml) } \\
\hline 0.125 & $0.6146 \pm 0.0184$ & $12.34^{*}$ \\
\hline 0.25 & $0.5740 \pm 0.0214$ & $18.13^{\star} \Delta$ \\
\hline 0.50 & $0.5014 \pm 0.0179$ & $28.33^{\star \Delta}$ \\
\hline 1.00 & $0.4324 \pm 0.0218$ & $38.33^{\star} \Delta$ \\
\hline \multicolumn{3}{|c|}{ rapamycin $(\mathrm{nmol} / \mathrm{ml})+$ cisplatin $(\mathrm{mg} / \mathrm{ml})$} \\
\hline $10+0.25$ & $0.4464 \pm 0.0263$ & $36.34^{\star \Delta}$ \\
\hline $20+0.25$ & $0.3201 \pm 0.0198$ & $54.36^{\star \Delta}$ \\
\hline $10+0.5$ & $0.2153 \pm 0.0315$ & $69.29 * \Delta$ \\
\hline $20+0.5$ & $0.1497 \pm 0.0326$ & $78.65^{\star \Delta}$ \\
\hline
\end{tabular}

${ }^{*} p<0.05$ vs. control group; $\Delta p<0.05$, comparison between two adjacent concentrations 
Table 2. Inhibitory effect of rapamycin combined with cisplatin on the proliferation of Hela cells

\begin{tabular}{lcc} 
Rapamycin & \multicolumn{3}{c}{ Cisplatin } \\
& $0.25 \mathrm{mg} / \mathrm{ml}$ & $0.5 \mathrm{mg} / \mathrm{ml}$ \\
$10 \mathrm{nmol} / \mathrm{ml}$ & 1.18 & 1.67 \\
$20 \mathrm{nmol} / \mathrm{ml}$ & 1.31 & 1.49
\end{tabular}

all $q$ values $>1.15$

than 1.15, as shown in Table 2. The result showed that the combination of rapamycin and cisplatin had an apparent effect on Hela cell proliferation, and they had a synergistic effect.

\section{Discussion}

Akt/mTOR is one of the cell proliferation-related signal pathways, and it is closely related to occurrence and development of multiple malignant tumors [8-10]. In recent years, mTOR has become a new target of molecular targeted therapy of tumors. Recent studies show that the mTOR specific inhibitor rapamycin has a treatment effect on a variety of tumors such as breast carcinoma, leukocythemia, liver cancer, gallbladder carcinoma, etc. [11-15]. However, at present there are fewer reports on the effect of this drug on cervical carcinoma at home and abroad.

The anti-tumor inhibition mechanism of the mTOR specific inhibitor rapamycin is mainly to inhibit conversion of the cell cycle from G1 phase to S phase, induce apoptosis of mutational tumor cells with P53 function deficiency, shut off the energy cycle route and block energy synthesis and utilization of the tumor cell by inhibiting mTOR and block tumor cell growth by inhibiting angiogenesis [16-18], which indicates that rapamycin achieves tumor inhibition by inhibiting tumor cell growth and proliferation and has a targeted antitumor effect on a number of pathways. Some studies have suggested that although rapamycin can kill tumor cells, it could attack normal cells, which was also confirmed in nude mice [19].

At present, chemotherapy of cervical carcinoma mainly uses cisplatin. However, its administration is usually stopped due to non-specific toxic side effects of cisplatin after multiple treatment courses of chemotherapy. Also, clinical effectiveness of drug resistance is not especially ideal. Yuan studied the effects of cisplatin on oophoroma and breast carcinoma tissues and found that increase of Akt activity was possibly one of the main factors causing drug resistance and thus causing failure of cisplatin chemotherapy [20]. Fraser et al. drew the same conclusion in a study of oophoroma [21]. Therefore, it is indicated that we can inhibit tumor cell growth by inhibiting Akt/mTOR to reverse drug resistance of cisplatin.

This experiment used simple rapamycin and cisplatin and their combination to carry out in vitro intervention of cervical carcinoma Hela cells, and the research results showed that simple application of rapamycin or cisplatin could inhibit human cervical carcinoma Hela cell strains and the inhibitory effect was dose-dependent. The combination application had a more apparent inhibitory effect on Hela cell proliferation than application of simple drugs. Also, q values of various drug combination groups were more than 1.15, suggesting that combination of the two had a synergistic effect. In a study on lung cancer, Wu et al. [15] proved that mTOR inhibitor could reverse cisplatin resistance and restore sensitivity of lung cancer resistance strains to cisplatin to cause apoptosis of resistant cells, and combination application had an apparent synergistic effect, which was in line with the study result about cervical carcinoma Hela cells in this study. Similarly, Bae-Jump et al. confirmed that combination of rapamycin and cisplatin had a synergistic inhibitory effect on endometrial carcinoma cells [22].

It can be found that rapamycin can really inhibit the growth of human cervical carcinoma Hela cells, and combination application of rapamycin and cisplatin can generate an apparent synergistic effect to increase the inhibition ratio of tumor cells. Therefore, rapamycin can be considered as a complementary drug. Under the premise of equivalent efficacy, concerted application of it and a chemotherapy drug can decrease the application amount of cisplatin, reduce toxic side effects of cisplatin and achieve a more satisfactory drug treatment effect of cervical carcinoma. Rapamycin has a broad-spectrum antitumor effect, and it has been safely and effectively used for tumor patients after organ transplantation. It is still necessary to investigate and explore the discussed application of rapamycin in tumor patients after non-organ transplantation.

This study was supported by the Social Development Foundation of Dalian Science and Technology Bureau.

The authors declare no conflict of interest.

\section{References}

1. Hidalgo $M$, Rowinsky EK. The rapamycin-sensitive signal transduction pathway as a targ for cancer therapy. Oncogene 2000; 19: 6680-6.

2. Oza AM. A phase study tensirolimus (CCl-779) in patients with metastatic and/or locally recurrent endometrial cancer. Proe $17^{\text {th }}$ Symp Mol Targets Cancer Thera 2005; 197: 269.

3. Amato RJ, Khan M. A phase I clinical trial of low-dose interferonalpha-2A, thalidomide plus gemcitabine and capecitabine for patients with progressive metastatic renal cell carcinoma. Cancer Chemother Pharmacol 2008; 61: 1069-73.

4. Johnston PB, Ansell SM, Colgan JP, et al. Phase trial of the oral mTOR inhibitor everolimus (RAD001) for patients with relapsed or refractory lymphoma. J Clin Oncol 2007; 25: 8055.

5. Chang SM, Wen P, Cloughesy T, et al.; North American Brain Tumor Consortium and the National Cancer Institute. Phase II study of CCl779 in patients with recurrent glioblastoma multiforme. Invest New Drugs 2005; 23: 357-61.

6. Asselin E, Mills GB, Tsang BK. XIAP regulates akt activity and caspase-3-dependent cleavage during cisplatin-induced apoptosis in human ovarian epithelial cancers. Cancer Res 2001; 61: 1862-8.

7. Meleod LE, Proud CG. TP deplection increases phosphorylation of inhibition of mTOR signaling. FEBS Lett 2002; 531: 448-52.

8. Lin HJ, Hsieh FC, Song H, Lin J. Elevated phosphorylation and activation of PDK-I, AKT pathway in human breast cancer. Br J Cancer 2005; 93: 1372-81.

9. Majumder PK, Sellers WR. Akt-regulated pathways in prostate cancer. Oncogene 2005; 24: 7465-74.

10. Tsurutani J, West KA, Sayyah J, Gills JJ, Dennis PA. Inhibition of the phosphatidyl-inositol 3-kinase/Akt/mammalian target of rapamycin pathway but not the MEK/ERK pathway attenuates laminin-medi- 
ated small cell lung cancer cellular survival and resistance to imatinib methylate or chemotherapy. Cancer Res 2005; 65: 8423-32.

11. Aleskog A, Norberg M, Nygren P, et al. Rapamycin shows anticancer activity in primary chronic lymphocytic leukemia cells in vitro, as single agent and in drug combination. Leuk Lymphoma 2008; 49: 2333-43.

12. Récher C, Beyne-Rauzy O, Demur C, et al. Antileukemic activity of rapamycin in acute myeloid leukemia. Blood 2005; 105: 2517-34.

13. Mondesire WH, Jian W, Zhang H, Ensor J, Hung MC, Mills GB, Meric-Bernstam F. Targeting mammalian target of rapamycin synergistically enhances chemotherapy-induced cytotoxicity in breast cancer cells. Clin Cancer Res 2004; 10: 7031-42.

14. Semela D, Piguet AC, Kolev M, Schmitter K, Hlushchuk R, Djonov V, Stoupis C, Dufour JF. Vascular remodeling and antitumoral effects of mTOR inhibition in a rat model of hepatocellular carcinoma. J Hepatol 2007; 46: 840-8.

15. Wu C, Wangpaichitr M, Feun L, Kuo MT, Robles C, Lampidis T, Savaraj N. Overcoming cisplatin resistance by mTOR inhibitor in lung cancer. Mol Cancer 2005; 4: 25.

16. Brazelton TR, Morris RE. Molecular mechanisms of action of new xenobiotic immunosuppressive drugs: tacrolimus (FK506), sirolimus (rapamycin), mycophenolate mofetil and leflunomide. Curr Opin Immunol 1996; 8: 710-20.

17. Faivre S, Kroemer G, Raumond E. Current development of mTOR inhibitors as anticancer agents. Nat Rev Drug Discov 2006; 5: 671-88.

18. Kwon YS, Kim JC. Inhibition of corneal neovascularization by rapamycin. Exp Mol Med 2006; 38: 173-9.

19. Podsypanina K, Lee RT, Politis C, et al. An inhibitor of mTOR reduces neoplasia and normalizes p70/S6 kinase activity in PTEN+/-mice. Proc Natl Acad Sci U S A 2001; 98: 10320-5.

20. Yuan ZQ, Richard IF, Gene ES, Coppola D, Nicosia SV, Cheng JQ. AKT2 inhibition of cispatininduced JNK/p38 and Bax activation by phosphorylation of ASK1: implication of AKT2 in chemoresistance. J Biol Chem 2003; 278: 23432-40.

21. Fraser M, Leung BM, Yan X, Dan HC, Cheng JQ, Tsang BK. p53 is a determinant of $\mathrm{X}$-linked inhibitor of apoptosis protein/Aktmediated chemo resistance in human ovarian cancer cells. Cancer Res 2003; 63: 7081-8.

22. Bae-Jump VL, Zhou C, Boggess JF, Gehrig PA. Synergistic effect of rapamycin and cisplatin in endometrial cancer cells. Cancer 2009; 115: 3887-96.

\section{Address for correspondence}

\section{Lu Han}

Dalian Obstetrics and Gynecology Hospital,

1\# Dunhuang Road Shakuo District,

Dalian 116033, China

e-mail: luhancn@126.com

Submitted: $\quad 8.06 .2012$

Accepted: $\quad 28.08 .2012$ 